\title{
Unexpected diagnosis in a patient with a liver mass: A case report
}

\section{Mohamed Hassan Ibrahim}

Internal Medicine Department, Gastroenterology and Hepatology Unit-Zagazig University, Egypt.

\section{Corresponding Author}

Prof. Dr. Mohamed Hassan Ibrahim

Internal Medicine Department, Hepatogastroenterology Unit - Zagazig University.

DOI: $\underline{\text { http://dx.doi.org/10.52378/asym7783 }}$

Email address: Edms2004@gmail.com

Sharkia, Zagazig, 44519.

Cell phone: +201066638535.

Received: April 25, 2019

Peer-review started: May 5, 2019

First decision: May 29, 2019

Revised: June 15, 2018

The second round of peer review (by journal editors): July 10, 2019

Accepted: July 13, 2019

Article in press: July 14, 2019

First online: July 25, 2019.

\begin{abstract}
Sarcoidosis is a rare inflammatory disease. It is characterized by granulomatous formation. The liver is the second most common site of involvement after the lung. Sarcoidosis of the liver is usually asymptomatic. Symptomatic cases can present with jaundice, itching, elevated liver enzymes, and the development of portal hypertension in rare situations. We, at this moment, submit a case of liver sarcoidosis in a patient with liver cirrhosis that presented with upper gastrointestinal bleeding. Upper digestive endoscopy revealed gastric varices. Ultrasonography of the abdomen revealed a suspicious liver mass for hepatocellular carcinoma. There is no nay cause of gastric varix in this patient apart from hepatic sarcoidosis (portal hypertension).
\end{abstract}




\section{Case report}

Treatment of the patient with corticosteroids leads to the complete disappearance of the liver mass. Despite the high incidence of HCC in Egypt due to the high prevalence of HCV infection, it is crucial to search for the rare causes of hepatic masses.

Keywords: liver mass; sarcoidosis, gastric varix

\section{Introduction}

Sarcoidosis is a chronic, multisystem disorder of unknown cause characterized in affected organs by an accumulation of T lymphocytes and mononuclear phagocytes, noncaseating epithelioid granulomas, and conditions of the healthy tissue architecture(1).

All body parts can be involved, but the organ most frequently affected is the lung. In addition, involvement of the skin, eye, liver, and lymph nodes is common.

Sarcoidosis is occasionally discovered in asymptomatic individuals, but more commonly, it presents abruptly over 1 to 2 weeks, or the affected individual develops symptoms over several months.

Acute or subacute sarcoidosis develops abruptly over a few weeks and represents 20 to $40 \%$ of all cases.

These individuals usually have constitutional symptoms such as fever, fatigue, malaise, anorexia, or weight loss. These symptoms are generally mild, but in $25 \%$ of the acute cases, the constitutional complaints are extensive(2).

Two syndromes have been identified in the acute group. First, Löfgren's syndrome is frequent in Scandinavian, Irish, and Puerto Rican females include the complex of erythema nodosum and xray findings of symptoms, including arthritis at the ankles and knees wrists, or wrists elbows (3).

Second, Lymphadenopathy is widespread in sarcoidosis. Intrathoracic nodes are enlarged in 75 to $90 \%$ of all patients; usually, this involves the hilar nodes, but the paratracheal nodes are commonly affected. Less frequently, there is an enlargement of subcarinal, anterior mediastinal, or posterior mediastinal nodes. In addition, peripheral lymphadenopathy is widespread, particularly involving the cervical, axillary, epitrochlear, and inguinal nodes(3).

Sarcoidosis involves the skin in $25 \%$ of patients. The most common lesions are erythema nodosum (4).

Although liver biopsy reveals liver involvement in 60 to $90 \%$ of patients, liver dysfunction is usually not clinically significant. Sarcoidosis generally involves the periportal areas. In addition, isolated granulomatous hepatitis can occur. Approximately 20 to $30 \%$ have hepatomegaly and 


\section{Case report}

biochemical evidence of liver involvement. Usually, these changes reflect a cholestatic pattern and include an elevated alkaline phosphatase level; the bilirubin and aminotransferase levels are only mildly elevated, and jaundice is rare. Rarely, portal hypertension can develop, as can intrahepatic cholestasis with cirrhosis(8).

Parotid enlargement is a classic feature of sarcoidosis. Bilateral involvement is the rule. The gland is usually non-tender, firm, and smooth. Xerostomia can occur; other exocrine glands are rarely affected(5).

The major problem in treating sarcoidosis is deciding when to treat it. Because the disease clears spontaneously in $50 \%$ of patients, and permanent organ disorders often do not improve with glucocorticoid treatment, clinicians have controversy regarding the criteria for treatment (2).

Methotrexate, 5 to $15 \mathrm{mg} /$ week in a single oral dose, is often used when contraindicated glucocorticoids (6).

\section{Presenting Concerns}

A 48-year-old man, employee, mild smoker, married, and have three children. The youngest is 11 years old. The patient presented with the first attack of upper GI bleeding in the form of hematemesis and melena. He had diabetes. Also, he had a total thyroidectomy three years ago and is on replacement therapy in the form of levothyroxine 150 ug per day.

\section{Clinical Findings}

Two weeks before admission, he had mild epigastric pain related to meals, dyspepsia, and altered bowel habit. He infrequently uses NSAIDs for back pain. There are no symptoms suggestive of other systems of affection. The patient was fully conscious; blood Pressure was $150 / 80 \mathrm{mmHg}$, pulse $90 / \mathrm{min}$ steady, average temperature. The patient was obese (BMI $45.2 \mathrm{~kg} / \mathrm{m} 2$ )with Mild bilateral lower limbs pitting edema. There was no jaundice or pallor. The liver was enlarged, firm, and tender. The spleen was enlarged, not tender. There are no ascites. Chest and heart examination were unremarkable

Table (1): clinical and laboratory, and radiological findings of the patient

At admission

White blood cell 7600

Platelet $\quad 328$ 


\begin{tabular}{|c|c|c|}
\hline \multicolumn{3}{|l|}{ Case report } \\
\hline Total Bilirubin & $0.8 \mathrm{mg} / \mathrm{dl}$ & \\
\hline Direct Bilirubin & $0.2 \mathrm{mg} / \mathrm{dl}$ & \\
\hline Albumin & $3.6 \mathrm{gm} / \mathrm{dl}$ & \\
\hline ALT/ AST & $35 / 46$ & \\
\hline ALP & 617 & \\
\hline $\mathrm{HBsAg}$ & -ve & \\
\hline HBCore Ab & -ve & \\
\hline HCVAb & -ve & \\
\hline Urea & 44 & \\
\hline Creatinine & 0.7 & \\
\hline TSH & 14.8 & \\
\hline $\mathrm{HbA} 1 \mathrm{C}$ & 6.1 & \\
\hline ESR & $>100$ & \\
\hline $\mathrm{LDH}$ & 419 & \\
\hline AFP & 3.1 & \\
\hline CXR & Normal & \\
\hline ECG & Normal & \\
\hline $\begin{array}{l}\text { Upper GI endosc } \\
\text { lipiodol. C-T abdc }\end{array}$ & $\begin{array}{l}\text { y revealed } \\
\text { len showed }\end{array}$ & $\begin{array}{l}\text { fundal varix injected with three ampoules of amcrylate and } \\
\text { numerous pre and para-aortic lymph nodes. The largest one }\end{array}$ \\
\hline
\end{tabular}




\section{Case report}

measures $2.5 \times 4.7 \mathrm{~cm}$. The liver is moderately enlarged with prominent left and caudate lobes and wavy contours.

Computed tomography revealed a well-defined exophytic isodense focal lesion $(2 * 2 \mathrm{~cm})$ in the right lobe displayed mild contrast enhancement in the arterial phase with rapid washout in the venous phase. In addition, the spleen is mildly enlarged.

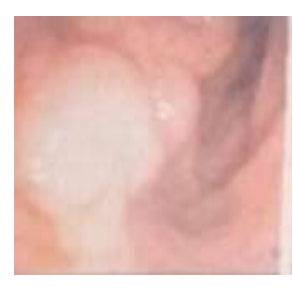

Fig (1) Endoscopic view shows fundal varix.

\section{Diagnostic procedure:}

Ultrasound-guided biopsy of the liver masses revealed a non-caseating granuloma with giant epithelial cells characteristic of sarcoidosis.

\section{Therapeutic Focus and Assessment}

The patient received treatment in the form of prednisolone $60 \mathrm{mg}$ orally per day for one month, and after that, the patient gradually withdrew the corticosteroids. After 3months, the hepatic mass completely disappears, and the fundal varix is obliterated.

\section{Follow up (after three months):}

Abdominal computed tomography: the liver is moderately enlarged with prominent left and caudate lobes and wavy contour. The spleen is mildly enlarged.

Upper Gl endoscopy revealed the site of previously injected fundal varix.

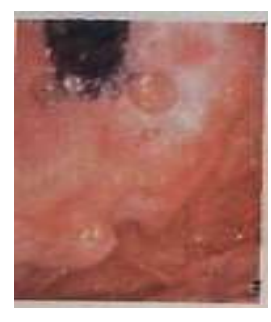

Fig (2) Endoscopic view shows the site of the injected fundal varix. 


\section{Case report}

Table (2): clinical and laboratory and radiological findings of the patient (follow-up)

At admission After four monthsAfter eight months

\begin{tabular}{|c|c|c|c|}
\hline Hemoglobin & $11.1 \mathrm{gm} / \mathrm{dl}$ & 12.3 & 12.2 \\
\hline White blood cells & 7600 & 8900 & 8100 \\
\hline Platelet & 328 & 213 & 225 \\
\hline Total Bilirubin & $0.8 \mathrm{mg} / \mathrm{dl}$ & 0.5 & 0.7 \\
\hline Direct Bilirubin & $0.2 \mathrm{mg} / \mathrm{dl}$ & 0.1 & 0.3 \\
\hline Albumin & $3.6 \mathrm{gm} / \mathrm{dl}$ & 3.9 & 3.7 \\
\hline ALT & 35 & 39 & 27 \\
\hline AST & 46 & 36 & 30 \\
\hline ALP & 617 & 160 & 122 \\
\hline ESR & $>100$ & 44 & \\
\hline LDH & 419 & 330 & \\
\hline ACE & $109 / 85$ & $74 / 85$ & \\
\hline TSH & 14.8 & 9.21 & 5.01 \\
\hline HbA1C & 6.1 & 10.2 & 6.3 \\
\hline
\end{tabular}




\section{Case report}

\section{Discussion}

The cells surrounding granulomas can produce increased amounts of ACE, and the blood level of ACE may increase in sarcoidosis. ACE elevated in $50 \%$ to $80 \%$ of those with active sarcoidosis. The blood level of ACE tends to rise and fall with disease activity. The ACE test can monitor the course of the disease and the effectiveness of corticosteroid treatment (7).

ACE moderately increased in various conditions and disorders, such as HIV, Histoplasmosis (fungal respiratory infection), Diabetes mellitus, Hyperthyroidism, Lymphoma, Alcoholic cirrhosis, Gaucher disease, Tuberculosis, Leprosy(7).

Although sarcoidosis is not a common cause of liver cirrhosis and portal hypertension(8), in our case, it may be the cause of the patient liver cirrhosis and gastric varices. The patient did not have viral hepatitis, HCV, or HBV infection. Also, the patient did not give any history of metabolic liver disease. Therefore, the treatment of hepatic sarcoidosis is debatable(2). Moreover, liver cirrhosis and vascular decompensation in our patient are additional questionable risk factors for the patient's treatment as corticosteroids are the main line of treatment. Despite that, we treat our patient with corticosteroids for three months with a good response (the disappearance of the hepatic masses and stabilization of the patient's clinical condition). Therefore, it is difficult to conclude that sarcoidosis is the only cause of liver cirrhosis and vascular decompensation. Still, the excellent response of the patient's condition to corticosteroids may assume that hepatic sarcoidosis is the principal cause of the patient chronic liver disease.

\section{Conclusion:}

Hepatic sarcoidosis can lead to portal hypertension, upper gastrointestinal bleeding, and liver masses. Also, treatment of hepatic sarcoidosis can lead to complete remission and the disappearance of liver masses.

\section{Informed Consent}

The patient provided his informed consent for the publication of this case report.

\section{Conflicts of interest}

The author declares no conflicts of interest.

\section{Footnotes}




\section{Case report}

CARE Checklist (2013) statement: The author has read the CARE Checklist (2013), and the manuscript was prepared and revised according to the CARE Checklist (2013).

Citation of this article: Ibrahim $\mathrm{MH}$. Unexpected diagnosis in a patient with a liver mass: A case report. African journal of gastroenterology and hepatology [Internet]. Egypt's Presidential Specialized Council for Education and Scientific Research; 2019 Jul 25;2(1):56-64. Available from: http://dx.doi.org/10.52378/asym7783

Peer- Reviewers: Emad Fawzy Hamed (Assistant professor of internal medicine), Mohamed Basha (lecturer of diagnostic radiology).

E- Editor: Salem Y Mohamed, Amr Shaban Hanafy, and Ayman M Sadek.

Copyright @. This open-access article is distributed under the Creative Commons Attribution License (CC BY). The use, distribution, or reproduction in other forums is permitted, provided the original author(s) and the copyright owner(s) are credited. The original publication in this journal is cited by accepted academic practice. No use, distribution, or reproduction is permitted, which does not comply with these terms. Disclaimer: claims expressed in this article are solely those of the authors and do not necessarily represent their affiliated organizations or those of the publisher, the editors, and the reviewers. Any product that may be evaluated in this article or claim that its manufacturer may make it not guaranteed or endorsed by the publisher. 


\section{Case report}

References

1. WALSH FB. Ocular importance of sarcoid: Its relation to uveoparotid fever. Archives of Ophthalmology. 1939;21(3):421-38.

2. Blich $\mathrm{M}$, Edoute Y. Clinical manifestations of sarcoid liver disease. Journal of gastroenterology and hepatology. 2004;19(7):732-7.

3. Kobak S, Sever F, Usluer O, Goksel T, Orman M. The clinical characteristics of sarcoid arthropathy based on a prospective cohort study. Therapeutic advances in musculoskeletal disease. 2016;8(6):220-4. Epub 2017/03/04.

4. Mana J, Marcoval J. Skin manifestations of sarcoidosis. Presse medicale (Paris, France : 1983). 2012;41(6 Pt 2):e355-74. Epub 2012/05/15.

5. Gadodia A, Bhalla AS, Sharma R, Thakar A, Parshad R. Bilateral parotid swelling: a radiological review. Dento maxillo facial radiology. 2011;40(7):403-14. Epub 2011/10/01.

6. Vorselaars AD, van Moorsel CH, Deneer VH, Grutters JC. Current therapy in sarcoidosis, the role of existing drugs, and future medicine. Inflammation \& allergy drug targets. 2013;12(6):369-77. Epub 2013/10/25.

7. Lieberman J. Elevation of serum angiotensin-converting-enzyme (ACE) level in sarcoidosis. The American journal of medicine. 1975;59(3):365-72. Epub 1975/09/01.

8. Bakker G, Haan Y, de Buy Wenniger LM, Beuers U. Sarcoidosis of the liver: to treat or not to treat? Neth J Med. 2012;70(8):349-56. 